\title{
COMISSÃO PRÓPRIA DE AVALIAÇÃO: DOIS LADOS DE UMA MESMA MOEDA
}

JOELMA DOS SANTOS BERNARDES JOSÉ CARLOS ROTHEN

\section{RESUMO}

Este artigo, que apresenta um estudo de caso realizado na Universidade Federal de São Carlos, tem a intenção de analisar e compreender se a autoavaliação institucional desenvolvida pela Comissão Própria de Avaliação se aproxima da perspectiva regulatória ou da emancipatória. Para tal, a pesquisa documental e o levantamento bibliográfico foram utilizados neste trabalho. Conchuiu-se que o processo de avaliação institucional demanda tempo, gera trabalho, conflito e nem toda a comunidade acadêmica percebe a importância desse tipo de avaliação para a gestão institucional. A Comissão mostrou ter dificuldade em discutir os resultados da avaliação institucional com a comunidade em virtude do pouco tempo estabelecido pela regulamentação, de forma que a autoavaliação institucional desenvolvida pela universidade aproximase, em alguns momentos, da avaliação regulatória e, em outros, da avaliação emancipatória.

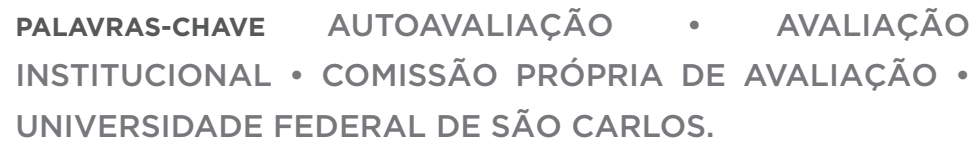




\section{RESUMEN}

Este artículo, que presenta un estudio de caso realizado en la Universidad Federal de São Carlos, tiene la intención de analizar y comprender si la autoevaluación institucional desarrollada por la Comisión Propia de Evaluación se aproxima de la perspectiva regulatoria o de la emancipadora. Para ello, la investigación documental y el relevamiento bibliográfico se utilizaron en este trabajo. Se concluyó que el proceso de evaluación institucional demanda tiempo, genera trabajo, conflicto y no toda la comunidad académica percibe la importancia de este tipo de evaluación para la gestión institucional. La Comisión mostró dificultad para discutir los resultados de la evaluación institucional con la comunidad en virtud del poco tiempo establecido por la reglamentación, de forma que la autoevaluación institucional desarrollada por la universidad se aproxima en algunos momentos de la evaluación regulatoria y, en otros, de la evaluación emancipadora.

\section{PALABRAS CLAVE AUTOEVALUACIÓN - EVALUACIÓN INSTITUCIONAL - COMISIÓN PROPIA DE EVALUACIÓN • UNIVERSIDAD FEDERAL DE SÃO CARLOS.}

\section{ABSTRACT}

This article, which presents a case study at the Federal University of São Carlos, aims to analyze and understand if the institutional selfevaluation developed by the Self-Evaluation Commission presents either a regulatory or emancipatory perspective. Thus, this study used documentary research and bibliographical survey. It was concluded that the institutional evaluation process demands time, generates work, conflict and not all the academic community understands the importance of this type of evaluation for institutional management. The Commission had difficulty in discussing the institutional evaluation results with the community due to the short time allotted by the regulation. Therefore, the institutional self-evaluation developed by the university at times approaches regulatory and, at others, emancipatory evaluation.

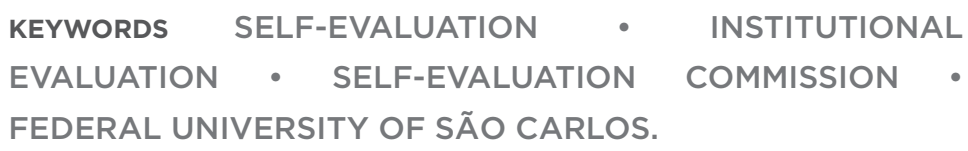




\section{INTRODUÇÃO}

"Regulação" e "emancipação" são termos recorrentes nas discussões a respeito do Sistema Nacional de Avaliação da Educação Superior (Sinaes). Isso porque a Lei n. 10.861 de 2004, a qual implantou o Sinaes, ao mesmo tempo que regula as instituições de ensino superior (IES), dá autonomia para o desenvolvimento dos processos de autoavaliação institucional.

O desenvolvimento dos processos de autoavaliação institucional, também denominada pela legislação de avaliação interna, deve ser conduzido, sistematizado e informado pela Comissão Própria de Avaliação (CPA), conforme está expresso na Lei do Sinaes. O resultado da autoavaliação produzido pela Comissão caracteriza-se como a prestação de contas da IES para o Estado e para a sociedade civil, na perspectiva da avaliação regulatória. Contudo, é possível abrir brechas na avaliação regulatória e estabelecer a avaliação emancipatória; isso se dá por meio de atores da comunidade acadêmica que ressignificam suas práticas mediante sua participação, seu envolvimento e comprometimento na avaliação institucional. 
Dessa maneira, o estudo de caso apresentado neste trabalho foi desenvolvido na Universidade Federal de São Carlos (UFSCar), com a finalidade de analisar e compreender se a autoavaliação institucional desenvolvida pela CPA se aproxima da perspectiva regulatória ou da emancipatória.

A avaliação emancipatória, conforme expõe Saul (1991), foi inspirada em três vertentes teórico-metodológicas: a avaliação democrática; a crítica institucional e criação coletiva; a pesquisa participante. Essa avaliação possibilita ao ator social libertar-se do condicionamento determinista, num "processo de descrição, análise e crítica de uma dada realidade, visando transformá-la” (SAUL, 1991, p. 61). Dessa maneira, o ator envolvido direta e/ou indiretamente com a avaliação pode atuar ativamente construindo a própria história e, com isso, afugentar ações deterministas e criar possibilidades de novas ações.

Por sua vez, a avaliação regulatória, segundo Afonso (2009), tem a tendência de valorizar a avaliação de resultado em detrimento da avaliação de processo, tornando comuns o ranqueamento e a classificação entre as instituições escolares. Com base nos resultados, aquelas que tiverem melhores indicadores recebem mais investimento; desse modo, a avaliação estabelece controle e regulação por parte do Estado-avaliador. ${ }^{1}$

O trabalho foi dividido em duas partes: a primeira delas, apresentada a seguir, é um levantamento bibliográfico para contextualizar as primeiras comissões, grupos e programas de avaliação da educação superior instituídos pelo Estado a partir da década de 1980. Entende-se que tais ações políticas contribuíram para a formulação e a implantação do Sinaes, anos depois. A segunda parte consistiu na análise da pesquisa documental a respeito da autoavaliação institucional desenvolvida pela CPA na instituição no período de 2004 a 2012. Para tal, os seguintes documentos foram analisados: Perfil do Profissional a ser Formado na UFSCar (2008), Plano de Desenvolvimento Institucional (2005), Portaria GR n. 397, de 19 de janeiro de 2010, Projeto de Avaliação do Ensino de Graduação da UFSCar (1994), Relatório de Autoavaliação Institucional da UFSCar 2011: Comissão Própria de Avaliação (2012),
1 Conforme aponta Afonso (2001, p. 25), o Estado-avaliador "no âmbito de trabalhos relativos às políticas de ensino superior, visa sobretudo sinalizar o facto de estar em curso a transição de uma forma de regulação burocrática e fortemente centralizada para uma forma de regulação híbrida que conjuga o controlo pelo Estado com estratégias de autonomia e auto-regulação das instituições educativas" 
Relatório de Autoavaliação Institucional da UFSCar 2012: Sistema Nacional de Avaliação do Ensino Superior (Sinaes) (2013) e Resolução ConsUni n. 652, de 11 de setembro de 2009.

\section{CONTEXTUALIZAÇÃO HISTÓRICA DAS POLÍTICAS PÚBLICAS DE AVALIAÇÃO DA EDUCAÇÃO SUPERIOR A PARTIR DA DÉCADA DE 1980}

Desde a década de 1980, o Estado vem modificando sua forma de atuação sobre as políticas públicas de avaliação da educação superior brasileira. As modificações foram influenciadas pelas mudanças político-econômicas em âmbito nacional e internacional.

É importante ressaltar que, antes da década de 1980, já ocorriam discussões a respeito de avaliação da educação superior; todavia, não ocorriam de forma sistematizada. Diante dessa elucidação, Barreyro e Rothen (2011, p. 75) apontam momentos históricos importantes na discussão da avaliação da educação superior:

Podemos recuar ao inquérito realizado por Fernando Azevedo na década de 1920 para O Estado de S. Paulo; ou aos levantamentos estatísticos promovidos pelo Instituto Nacional de Estudos Pedagógicos a partir dos anos de 1940. Já na década de 1960, ao relatório do consultor da Agência dos Estados Unidos para o Desenvolvimento Internacional (USAID), Rudolf Atcon. Pode ser citada a avaliação da Reforma Universitária, proposta pelo ConseIho Federal de Educação, no início da década de 1970, e realizada pela Universidade Federal da Bahia, em parceria com o Ministério da Educação (MEC). Houve, também, em meados da década de 1980 o relatório de uma comissão de notáveis que discutiu os rumos da universidade brasileira. Destaque-se ainda a introdução na Constituição de 1988 da obrigatoriedade da iniciativa privada submeter-se à avaliação do Poder público.

Na década de 1980, as discussões a respeito de como e o que avaliar nas IES brasileiras eram efervescentes em âmbito 
governamental e acadêmico. De tal forma que tomaram proporções cada vez maiores com a finalidade de saber qual seria o resultado da avaliação e também quais seriam o desdobramento e o impacto do processo avaliativo. De sorte que a Associação Nacional dos Docentes de Ensino Superior (Andes), em 1982, propôs estudo específico a respeito da avaliação institucional. Em decorrência dessa reivindicação, em 1983 o Ministério da Educação (MEC) instituiu o Programa de Avaliação da Reforma Universitária (Paru) (LEITE, 2000). O Paru é entendido neste trabalho como o ponto de partida para as discussões sistematizadas a respeito da avaliação, isso por conta da participação não apenas do Estado, mas também de diversos atores sociais, os quais discutiram quais seriam os caminhos para o ensino superior.

Inicialmente o Estado concedeu maior autonomia aos atores envolvidos, com a discussão do ensino superior por meio do Paru. Conforme relata Leite (2000), o programa buscava efetivar a gestão democrática nas IES e também o financiamento, a carreira, as tomadas de decisões e as políticas de ensino, pesquisa e extensão. Como procedimento metodológico, recorreu-se à aplicação de questionário aos discentes, aos dirigentes e aos docentes do ensino superior, estando previstos o diagnóstico, o debate dos resultados e a elaboração de um relatório para o Conselho Federal de Educação. Apesar de estarem previstas tais ações, o Paru foi desativado em 1983, um ano depois de seu surgimento, e, por consequência, não apresentou os resultados de sua avaliação.

Em 1985, por meio do Decreto n. 91.177, foi instituída a Comissão Nacional de Reformulação da Educação Superior, também conhecida como Comissão de Notáveis, que buscava "a reformulação da educação superior, no marco da redemocratização do país, com a instauração da Nova República” (BARREYRO; ROTHEN, 2008, p. 136). Havia o anseio da comunidade acadêmica e de entidades representativas para a melhoria das políticas públicas para o ensino superior. Entretanto, o relatório final da Comissão de Notáveis previa a implantação do perfil empresarial na universidade com prestação de serviço com eficiência, eficácia e produtividade, além de buscar implantar o sistema meritocrático para 
orientar o financiamento da educação superior. A esse respeito, Dias Sobrinho (2002, p. 57) relata que algumas sugestões, presentes no relatório da Comissão, foram retomadas e aplicadas no governo de Fernando Henrique Cardoso anos depois:

Nesse documento já constam muitas sugestões que vieram a serem colocadas em prática após 1995 pelo governo de Fernando Henrique Cardoso como a abertura para a privatização, diversidade, pluralidade, autonomia vinculada ao desempenho e, portanto, a uma avaliação controladora, a linguagem da excelência, eficiência e produtividade, a gestão eficaz, enfim a racionalidade quantitativista e objetivista que já vigorava no Reino Unido e nos Estados Unidos.

Em fevereiro de 1986, o MEC apresentou o Grupo Executivo para a Reformulação do Ensino Superior (Geres), composto por acadêmicos, burocratas do governo e empresários. O grupo propôs ao MEC um programa de reformulação do ensino superior. Segundo expõe Leite (2000), ao final dos trabalhos, o Geres exibiu um relatório que pretendia ranquear as IES. Logo, a comunidade acadêmica analisou a situação e reagiu contra essa intenção de ranqueamento das instituições de acordo com os resultados da avaliação.

Nota-se que as comissões e grupos criados pelo Estado tinham o objetivo de debater os rumos das políticas públicas do ensino superior, buscando adequar as novas exigências das políticas nacionais e internacionais. Por conseguinte, o Conselho de Reitores das Universidades Brasileiras (Crub), o Sindicato Nacional dos Docentes de Ensino Superior (Andes-SN) e outras instâncias sindicais e da sociedade civil manifestaram-se em resposta aos programas oficiais do Estado defendendo um "padrão único de qualidade para a universidade" (WEBER, 2010, p. 1253).

O Período Militar findou em 1984, quando o país passou por um momento de redemocratização que se refletiu nas IES públicas. Em 1990, no governo de Fernando Collor de Mello, houve uma tentativa de implantar o Estado-avaliador para regular e para controlar as IES; contudo, ocorreram 
manifestações de atores sociais contra tais medidas (BRASIL, 2003).

Já no governo de Itamar Franco aconteceram avanços nas políticas públicas para avaliação da educação superior. Em 1993, a Portaria n. 130, editada pela Secretaria da Educação Superior (SESu), instituiu o Programa de Avaliação Institucional das Universidades Brasileiras (Paiub), o qual era coordenado pela Comissão Nacional de Avaliação. O objetivo do programa era estabelecer diretrizes e viabilizar a implementação do processo de avaliação institucional nas universidades brasileiras (BRASIL, 2003).

No Paiub uma comissão externa e outra interna davam direcionamento aos processos avaliativos que ocorriam nas IES que aderiam ao programa. A comissão externa era designada pelo MEC, tinha como função acompanhar ações desenvolvidas pelas instituições federais para o recebimento do financiamento. No que diz respeito à comissão interna, também chamada de Comissão Permanente de Avaliação (CPA), tinha a finalidade de conduzir os processos de avaliação que ocorriam dentro da IFES para a elaboração do relatório final a ser encaminhado à Comissão Nacional de Avaliação. Pode-se perceber que a CPA desencadeava na instituição uma autoavaliação institucional, sobre a qual a comunidade acadêmica poderia refletir e se autoconhecer, identificando os aspectos que necessitariam de melhoria e de avanço. Com o Paiub, buscou-se o aperfeiçoamento da qualidade institucional das IES públicas, bem como o respeito à diversidade existente em cada uma, viabilizando, de forma mais efetiva, o financiamento por meio do planejamento apresentado ao MEC.

Ristoff (2005) expõe que era importante as IES públicas atingirem consciência da qualidade da avaliação institucional e ressalta que, para isso, seria necessário estabelecer um elo entre as três frentes que a compõem: o ensino, a pesquisa e a extensão. O sucesso da avaliação institucional só ocorreria com essas três frentes juntas, uma ou duas não seriam o suficiente para um desenvolvimento com qualidade. Juntamente com os princípios norteadores do Paiub, havia o diálogo e a negociação entre a comunidade acadêmica e a SESu do MEC. 
Conforme relatam Barreyro e Rothen (2006), no primeiro mandato do presidente Fernando Henrique Cardoso (FHC), o ministro da Educação Paulo Renato Souza implantou uma sequência de doze medidas provisórias (MP) concernentes ao processo de avaliação do ensino superior. Pouco tempo depois, a Lei n. 9.131, de 1995 (BRASIL, 1995), foi sancionada. Nela, o parágrafo $7^{\circ}$ previa o início do Exame Nacional de Curso (ENC), popularmente chamado de "Provão". De acordo com Leite (2000), o Provão teve como objetivo avaliar o ensino das universidades; contudo, aqueles estudantes que fossem selecionados para a prova e não a fizessem, não receberiam o diploma ao final do curso de graduação. Em 1996, o Decreto n. 2.026 foi editado, o que deu início aos procedimentos para a avaliação de cursos do ensino superior, além de estabelecer os principais indicadores de desempenho.

Em 1996, a Lei de Diretrizes e Bases da Educação Nacional (LDB), Lei n. 9.394, foi sancionada. Dessa lei decorreu a expansão da oferta de ensino superior, o que intensificou o processo de avaliação realizado pelo Provão. O resultado da avaliação seria divulgado para a comunidade acadêmica e para a sociedade civil como forma de prestação de contas dos investimentos recebidos e, assim, legitimava-se a política de regulação das IES. No entanto, as conjunturas político-econômicas foram modificadas e, com isso, o Paiub foi sendo, aos poucos, por meio de manobras políticas, desarticulado.

Em 2003, na gestão do ministro Cristovam Buarque, foi aplicada a última edição do ENC aos discentes concluintes. Ao final daquele mesmo ano, em dezembro, foi editada a Medida Provisória n. 147, instituindo o Sistema Nacional de Avaliação e Progresso do Ensino Superior. A MP tinha a finalidade de avaliar a capacidade do ensino, do conhecimento e da responsabilidade institucional. Assim, nos parágrafos $1^{\circ}$, $2^{\circ}, 3^{\circ}$ e $4^{\circ}$ do artigo $13^{\circ}$, tem-se que:

Art. 13. As instituições de ensino superior, públicas ou privadas, ficam obrigadas a constituir Comissão Própria de Avaliação - CPA, no prazo de noventa dias, a contar da publicação desta Medida Provisória. 
§1ำ As CPA responsabilizar-se-ão pela condução dos processos de avaliação internos das instituições, pela sistematização e pela prestação das informações solicitadas pela CONAPES.

\$2- As CPA deverão ser constituídas em ato do dirigente máximo da instituição de ensino superior, ou por previsão no seu próprio estatuto ou regimento.

§3ำ As CPA terão atuação autônoma em relação a conselhos e demais órgãos colegiados existentes nas instituições de ensino superior.

§4ํNa composição das CPA, observar-se-á a participação de todos os segmentos da comunidade universitária e da sociedade civil organizada, sendo vedada a instituição de comissão que privilegie a maioria absoluta de um dos segmentos. (BRASIL, 2003)

Pode-se observar que as IES públicas e privadas deveriam constituir uma CPA para conduzir os processos internos de avaliação institucional e, em seguida, sistematizar e informar à Comissão Nacional de Avaliação e Progresso do Ensino Superior (Conapes).

O ENC foi aplicado até o primeiro ano do governo do presidente Luiz Inácio Lula da Silva. A Medida Provisória n. 147 foi alterada e convertida na Lei n. 10.861, que instituiu o Sinaes e faz uso da perspectiva da avaliação regulatória e da avaliação emancipatória, pois controla a oferta de educação superior por meio de instrumento avaliativo e prestação de contas ao Estado e à sociedade civil, como também dá autonomia no desenvolvimento da avaliação interna nas instituições.

Pode-se compreender que a avaliação institucional possibilita à IES adquirir maior conhecimento de si por meio da autoavaliação ao identificar avanços e melhorias desde a estrutura física até o compromisso social. A partir disso, os processos de autoavaliação institucional podem ser conduzidos e sistematizados pela CPA. Isso se evidencia nos incisos I e II do artigo $11^{\circ}$ da Lei do Sinaes, que descrevem a Comissão:

Art. 11. Cada instituição de ensino superior, pública ou privada, constituirá Comissão Própria de Avaliação - CPA, no prazo de 60 (sessenta) dias, a contar da publicação desta Lei, com as atribuições de condução dos processos 
de avaliação internos da instituição, de sistematização e de prestação das informações solicitadas pelo INEP, obedecidas as seguintes diretrizes:

I - constituição por ato do dirigente máximo da instituição de ensino superior, ou por previsão no seu próprio estatuto ou regimento, assegurada a participação de todos os segmentos da comunidade universitária e da sociedade civil organizada, e vedada a composição que privilegie a maioria absoluta de um dos segmentos;

II - atuação autônoma em relação a conselhos e demais órgãos colegiados existentes na instituição de educação superior. (BRASIL, 2004)

Nota-se que a Lei do Sinaes manteve, portanto, o que foi editado na MP n. 147 a respeito da constituição da CPA, pois pode ser constituída pelo dirigente da IES ou pelo regimento próprio; ter a participação de representante de cada segmento da IES; ter representatividade da sociedade civil, além de ter caráter autônomo, ou seja, não ser subordinada a conselhos, a colegiados e demais órgãos da instituição.

\section{UM OLHAR PARA A AVALIAÇÃO INSTITUCIONAL DA UNIVERSIDADE FEDERAL DE SÃO CARLOS A PARTIR DA DÉCADA DE 1990}

A UFSCar foi criada por meio de articulação e barganha política no período da Ditadura Militar. Por esse fator, os primeiros gestores da instituição exerciam o perfil autoritário na condução e no desenvolvimento da universidade. Sguissardi (1993, p. 192) acrescenta que:

A UFSCar surge sob o signo de um projeto indefinido, mas como obra de ação política precisa que trazia as marcas de regime de exceção então vigente. Sua certidão de nascimento foi um decreto e não uma lei ou, mesmo, um decreto-lei. Esta afronta às normas jurídicas, em maio de 1968, fala por si própria dos sinais distintivos daquele tempo.

Essa indefinição apontada por Sguissardi se caracteriza pela forma como os políticos articularam-se para a implantação 
da universidade, a qual incialmente tinha a intenção de ofertar apenas o ensino e a pesquisa. Porém, ao longo das décadas de 1970 e 1980, vários atores da comunidade acadêmica exigiram incansavelmente a oferta do curso de extensão, bem como uma instituição mais democrática e plural.

Até o início da década de 1990, não ocorriam com regularidade na universidade processos de avaliação institucional, as exceções se davam de forma isolada e não sistematizada, dando maior ênfase aos procedimentos didático-pedagógicos. Rothen et al. (2013) acrescentam que em 1989, após a criação da Pró-Reitoria de Graduação (ProGrad), ampliaram-se as ações institucionais, dentre elas se destaca a avaliação de sete cursos de graduação. Nota-se que os atores que compunham a instituição na época estavam comprometidos, envolvidos e se sentiam responsáveis pela melhoria do ensino de graduação, pois já havia a intenção de desenvolver avanços para essa etapa de ensino. Dessa forma, a avaliação que acontecia na universidade era feita de maneira focal. Em meados da década de 1990, a IES aderiu voluntariamente ao Paiub, o que ocasionou o início de processos de avaliação institucional com regularidade, sistematização e de maneira global.

A partir da adesão da universidade ao Paiub, se possibilitou, de forma efetiva, o desenvolvimento do projeto intitulado "Avaliação do Ensino de Graduação na UFSCar", "aprovado pela Câmara de Graduação (Parecer CaG n. 089/94, de 29/03/94) e pelo Conselho de Ensino e Pesquisa (Parecer CEPE 554/94, de 05/04/94)" (UFSCar, 1994, p. 2), de modo que as justificativas para o desenvolvimento do projeto foram:

As razões político-sociais, científicas e técnicas de investir na avaliação do ensino de graduação são suficientemente fortes, seja pela quantidade de pessoas envolvidas, pela relevância social ou, ainda, pela ausência sistematizada e contínua de avaliação neste nível, dispensando, portanto, outras justificativas. (UFSCar, 1994, p. 5)

O "Projeto de Avaliação do Ensino de Graduação na UFSCar" fomentou o desenvolvimento de ações, como a elaboração do Projeto Pedagógico de Curso (PPC) de cada curso. Até aquele momento, os cursos não possuíam PPC, apenas a 
matriz curricular, a qual somente apresentava as disciplinas ofertadas durante a graduação. Outra ação de destaque foi o "Perfil Profissional a ser Formado na UFSCar": à medida que as coordenações de cursos construíam seus relatórios e entregavam para a gestão da universidade, esta os analisava. Por meio dessa análise, percebeu-se a necessidade de se discutir qual era o perfil profissional que estava sendo formado na universidade. Nesse sentido, a gestão da IES iniciou um período de discussões a respeito da formação acadêmica, a organização e o planejamento das atividades foram feitas pela ProGrad. Como metodologia, realizaram-se mesas-redondas, palestras e oficinas de trabalho, com o objetivo de "fornecer subsídios às equipes encarregadas da revisão dos currículos, na perspectiva da sua inovação" (UFSCar, 2008, p. 1).

Compreende-se, assim, que, para a construção do "Projeto Avaliação do Ensino de Graduação na UFSCar", houve uma multiplicidade de valores e de interesses, pois foi uma criação coletiva. Ocorreram trocas de informação, de conhecimento, de avanço e de necessidade alicerçadas no diálogo, na negociação e na síntese de resultados para informar a comunidade acadêmica, conforme está exposto no "Projeto de Avaliação do Ensino de Graduação":

O Plano de Ação da atual Reitoria resultou da incorpo-
ração de sugestões, levantadas junto aos departamentos
acadêmicos e setores administrativos, estudantes de gra-
duação e de pós-graduação, à Proposta de Ação apresen-
tada à comunidade, por ocasião do processo sucessório.
A diretriz metodológica privilegiada no Plano é torná-lo
instrumento de participação e integração de diferentes
segmentos, com a proposta de discussão permanente,
pelo menos a cada ano de sua execução, pretende-se que
a construção do projeto - UFSCar seja aperfeiçoada a par-
tir do engajamento. (UFSCar, 1994, p. 5)

Cabe destacar outros documentos produzidos no decorrer do desenvolvimento do "Projeto de Avaliação do Ensino de Graduação": 1) Atribuições gerais das diferentes instâncias no que se refere ao ensino de graduação; 2) Avaliação externa: apresentação dos processos de avaliação e de elaboração 
do relatório final de avaliação do ensino de graduação no âmbito da Coordenação de Curso; 3) Indicadores de avaliação da Coordenação de Curso; 4) Instrumentos gerais para elaboração do relatório de avaliação do curso; 5) Planejamento da operacionalização das diferentes etapas da autoavaliação/ cronograma; 6) Relação de indicadores utilizados no âmbito da Coordenação de Curso; 7) Relação dos roteiros elaborados e dos responsáveis pela coordenação de sua aplicação; 8) Relatório de avaliação externa; 9) Relatório do $1^{\circ}$ Encontro do Fórum de Licenciatura da UFSCar; 10) Relatórios de desenvolvimento do projeto; 11) Roteiro de avaliação para as turmas de alunos; 12) Roteiro para elaboração do relatório final sobre o ensino de graduação no âmbito da Coordenação de Curso; 13) Roteiros de questões para avaliação, síntese das palestras e mesas-redondas ocorridas na primeira fase de implementação do Projeto de Avaliação; 14) Sugestões para a melhoria da formação pedagógica nos cursos de licenciatura da UFSCar, extraídas dos respectivos relatórios de autoavaliação; 15) Sugestões para a melhoria dos cursos de licenciatura da UFSCar, extraídas dos respectivos relatórios de avaliação externa; 16) Valores buscados pela Universidade Federal de São Carlos em seu ensino de graduação. Entende-se, dessa maneira, que o "Projeto de Avaliação do Ensino de Graduação” foi um dos precursores da cultura de avaliação e da participação na universidade de forma sistemática. Outro fato relevante é que a gestão da IES utilizou os resultados da avaliação para a melhoria do planejamento institucional, especificamente para o ensino de graduação.

Observa-se que o desenvolvimento desse projeto implicou uma série de ações dentro da universidade e, para isso, houve o desempenho de atores que coordenaram a avaliação. Cabe ressaltar que no processo avaliativo é imprescindível haver atores que o coordenem, porque a atuação deles direciona as próximas etapas a serem desenvolvidas na avaliação, possibilitando a discussão e a negociação de prazos e metas e a definição de ações urgentes e/ou emergentes diante da adversidade de pouco recurso financeiro e/ou humano, e gera credibilidade e confiança nos demais membros da comunidade acadêmica. A esse respeito, Nevo (2001) afirma 
que a presença de um ator que esteja familiarizado com a condução do processo avaliativo faz com que haja um momento de refletir, de definir objetivos e de disseminar a responsabilização nas tomadas de decisão tanto para a gestão como para a comunidade acadêmica.

Posteriormente ao projeto na IES, em 2002 iniciou-se a constituição do "Plano de Desenvolvimento Institucional" (PDI), pois se entendia que, naquele momento, era importante estabelecer um plano norteador das ações que seriam desenvolvidas na instituição durante os próximos dez e quinze anos. Cabe evidenciar que essa tomada de decisão da gestão da universidade não está desvinculada nem desinteressada das políticas públicas da educação superior, haja vista que, no mesmo período histórico, o Governo Federal sancionou o Plano Nacional de Educação (PNE), que determinava prazo para as IES públicas e privadas apresentarem seus PDIs. Dessa maneira, a comunidade acadêmica iniciou um novo movimento, com enfoque na construção do PDI, que, por sua vez, era diferente do projeto de avaliação, já que abrangeu todos os setores da instituição e não tinha a pretensão de realizar processos de avaliação somente, mas também de criar diretrizes, planos e projetos que fundamentavam os quatro aspectos que constituem a instituição: o físico, o organizacional, o acadêmico e o ambiental. Para cada aspecto foi constituído um grupo de trabalho (GT) responsável por apresentar um relatório que contemplasse os seguintes critérios:

- preparar os subsídios necessários à reflexão da comunidade, tais como informações, parâmetros e fundamentos teóricos, conhecimentos e experiências acumulados na Universidade e fora dela;

- propor e conduzir discussões utilizando procedimentos favorecedores da construção coletiva - métodos, instrumentos e ferramentas de governo que permitissem a captação e processamento de diferentes contribuições; e

- sistematizar as propostas recolhidas nas diferentes estratégias utilizadas.

(UFSCar, 2005, p. iii) 
A confecção dos relatórios sucedeu-se com a participação da comunidade acadêmica por meio de reflexão, informação, palestra, consulta, entrevista, questionário, fórum e seminário. As formulações proporcionaram diretrizes para cada aspecto e, em seguida, foram encaminhadas para apreciação ao Conselho Universitário (ConsUni), que os aprovou.

Em dezembro de 2002 ocorreu a Conferência de Busca do Futuro da UFSCar com o objetivo de sistematizar e de identificar o entendimento comum nas propostas levantadas pelos quatro aspectos e formular o esboço do PDI, que se caracterizou como:

A sistematização das contribuições decorrentes do debate sobre cada um dos aspectos e nos diversos momentos de interação entre eles buscou consolidar um raciocínio integrado em relação à Instituição. Juntas, as peças do quebra-cabeça, marca do processo, mais que somar as partes, formaram um quadro articulado, do qual foi possível extrair os princípios, as diretrizes gerais e específicas para o desenvolvimento da Universidade, decorrentes de um amplo debate na comunidade e aprovados no seu Conselho Universitário. O envolvimento efetivo da comunidade acadêmica no processo confere qualidade e legitimidade ao PDI e vem permitindo à nova administração desta Universidade (gestão 2004-2008) e a toda a comunidade acadêmica enfrentar o desafio que se apresenta: a operacionalização e implantação de seu Plano de Desenvolvimento Institucional, a partir do desdobramento das diretrizes aprovadas em ações. (UFSCar, 2005, p. v)

A sistematização e a identificação das ideias em comum constituíram 26 diretrizes gerais de acordo com os quatro aspectos. Com base nessas diretrizes, foram geradas diretrizes específicas estruturadas em temas, a saber: processo de formação; ampliação, acesso e permanência na universidade; produção e disseminação do conhecimento; capacitação dos servidores da instituição; ambiente adequado; organização e gestão e desenvolvimento. Isso possibilitou à IES fundamentar o planejamento da gestão na definição dos objetivos e das 
ações a serem desenvolvidas. A metodologia utilizada para a formulação do documento foi o planejamento estratégico situacional para o setor público, o que pressupõe o acompanhamento e a revisão do planejamento (UFSCar, 2005).

Nesse momento histórico, a instituição passou por mudanças estruturais e conjunturais, pois houve a necessidade de repensar o espaço, o acolhimento e a infraestrutura, bem como as regulamentações federais que impactaram diretamente nas tomadas de decisão. Uma das regulamentações federais que impactou a IES foi a Lei n. 10.861, que instituiu o Sinaes.

A Lei do Sinaes determinou que as IES constituíssem sua CPA no prazo de 60 dias após a promulgação da lei; isso ocorreu no ano de 2004. Nesse período, o PDI da UFSCar estava sendo finalizado. Para não desarticular as ações desenvolvidas no PDI, a coordenação da primeira CPA entendeu que não era o momento de estabelecer um novo processo de avaliação institucional, mas de somar as ações que já estavam sendo desenvolvidas. Após a comissão postar o primeiro relatório de autoavaliação no site do Instituto Nacional de Estudos e Pesquisas Educacionais Anísio Teixeira (Inep), não foram evidenciados maiores avanços nos processos de avaliação institucional dentro da universidade. Dessa maneira, a CPA não se tornou suficientemente conhecida na instituição a ponto de ser então reconhecida pela comunidade acadêmica até o final do segundo mandato em 2009. Em maio desse mesmo ano, a Comissão Externa do MEC/Inep realizou uma visita in loco na UFSCar, na qual constatou a fragilidade da CPA na condução e na sistematização dos processos de avaliação institucional dentro da universidade. De modo que o parecer da Comissão Externa considerou:

[...] como pontos fortes as políticas de ensino, pesquisa e extensão, em especial a indissociabilidade das três atividades, e as ações de responsabilidade social da UFSCar. O parecer aponta também a independência e autonomia dos nossos colegiados e a participação dos segmentos da comunidade nos processos decisórios. Algumas críticas foram apontadas e se referem a: constituição da CPA de 2008, por uma maioria de docentes ao final dos 
trabalhos (os alunos estavam formados e os técnico-administrativos tinham se desligado); divulgação insatisfatória, entre o corpo social da IES, do processo de autoavaliacão promovido pela CPA; não implantação da Ouvidoria; existência de condições institucionais para os técnicos administrativos (TAs) apenas compatíveis com referencial mínimo de qualidade; limitação dos espaços de convivência frente ao crescente número de alunos ingressantes. (UFSCar, 2013, p. 34)

Em decorrência dessa situação, a CPA foi institucionalizada na universidade por meio da Resolução ConsUni n. 652, de 11 de setembro de 2009. Nessa resolução, foram delimitados o período de duração do mandato, a quantidade de membros, a atuação na IES e as competências de acordo com a Lei do Sinaes. $O$ artigo $9^{\circ}$ também estabelece que a Universidade forneça à CPA condições materiais, de infraestrutura e de recurso humano para o desenvolvimento das atividades, além da liberdade de acesso às informações concernentes à IES, com exceção das sigilosas.

Após a institucionalização da comissão na UFSCar, a Portaria GR n. 397, de 19 de janeiro de 2010, nomeou uma nova equipe, que ao longo dos dois anos de mandato divulgou e informou as ações desenvolvidas para a comunidade acadêmica, buscando sensibilizá-la para a participação nos processos de autoavaliação institucional e demostrando a importância da avaliação na IES. Dentre as ações, cabe destacar que a nova equipe da CPA considerou:

[...] a crítica da Comissão Externa de Avaliação referente à divulgação insatisfatória, entre o corpo social da IES, do processo de autoavaliação promovido pela CPA, tomou algumas iniciativas para uma maior divulgação do seu trabalho. Primeiramente divulgou no Portal da UFSCar o Projeto de Autoavaliação de 2010 solicitando que a comunidade tomasse conhecimento e apresentasse sugestões durante o mês de maio. A coordenadora providenciou, ainda, a confecção de um site da CPA (www.cpa.ufscar. br) para divulgação do seu trabalho com possibilidade de consultas ao Projeto, legislação, pautas e atas das 
reuniões, além de notícias referentes à avaliação. A CPA programou apresentações nos Conselhos, durante os meses de agosto e setembro de 2010, para divulgar o trabaIho de avaliação. Realizou em novembro uma palestra na I Jornada Científica de Sorocaba. [...] Ainda com o objetivo de divulgar os trabalhos da CPA e incentivar a participação de coordenadores de curso, professores, alunos e ex-alunos nos trabalhos de preparação da avaliação de cursos e da UFSCar da perspectiva dos egressos, a Coordenadora deu uma entrevista ao INFORMANDO de 01 a 14 de outubro - jornal quinzenal da UFSCar. Também coordenou a confecção de um folheto com o mesmo objetivo. Este folheto foi distribuído no dia 04/12/2010 durante uma festa de comemoração dos 40 anos da UFSCar, para servidores e ex-alunos. (UFSCar, 2012, p. 233)

Percebe-se que, a partir do momento em que foi institucionaliza, a CPA passou a ser conhecida e reconhecida pela comunidade acadêmica. Um fator de destaque para esse (re)conhecimento foi que a universidade forneceu maior condição material, infraestrutura e recursos humanos para o desenvolvimento de suas atividades avaliativas.

Os resultados da avaliação institucional não foram discutidos com a comunidade em virtude do pouco tempo destinado ao processo avaliativo determinado pelo Inep. Isso porque, em 2009, foi editada a Portaria MEC n. 821 (BRASIL, 2009), que determina que a entrega do relatório de autoavaliação institucional passa a ser anual e não mais bianual.

Diante desse curto prazo para a confecção de relatório de autoavaliação institucional, pode-se perceber a atuação da regulação e do controle do Estado dentro da IES. Atuação esta que gerou uma dificuldade para estabelecer a cultura de avaliação, pois a equipe de CPA e a comunidade acadêmica ficaram desprovidas de tempo hábil para consolidar processos de discussão e de reflexão a respeito dos resultados apontados na autoavaliação institucional. O tempo destinado para a elaboração do relatório de autoavaliação institucional é um dos desafios a serem enfrentados pelas CPAs, pois é imprescindível haver tempo para que o processo de discussão seja 
permeado pelo diálogo - entendido como a possibilidade das trocas de experiências, inquietações e dificuldades -, como também para socializar avanços, conquistas e metas entre os pares. Esse momento de diálogo conduz ao processo de negociação por meio dos resultados da avaliação. Isso significa que a comunidade, com base nos resultados da avaliação, tem autonomia para decidir qual é o melhor caminho para a tomada de decisão institucional.

Conforme esclarece Saul (1991), a avaliação emancipatória é um processo longo e árduo para os envolvidos, uma vez que é preciso haver a descrição, a análise e a crítica à realidade para que os atores possam tomar consciência de que se trata de uma criação coletiva que desperta a responsabilidade, a autonomia e o compromisso no planejamento da avaliação emancipatória. Assim, é necessário haver trocas de informação, de diálogo e negociação.

A consolidação da cultura de participação não é algo fácil, linear e homogêneo, por isso é conflituosa dentro da instituição, pois existem interesses internos e externos que interferem na realidade institucional, uma criação coletiva da própria história da IES.

Há outro fator relevante na atuação da CPA ao longo da análise de sua trajetória. Durante o desenvolvimento dos processos de autoavaliação institucional, a comissão estabeleceu parceria com outras instâncias institucionais da universidade para auxiliar e/ou desenvolver a autoavaliação institucional. Dentre as parcerias estabelecidas entre 2004 e 2012, destacam-se as seguintes: o Centro de Estudo do Risco (CER) do Departamento de Estatística; a Divisão de Desenvolvimento Pedagógico (DiDPed); a Divisão de Gestão e Registro Acadêmico (DiGRA); a ProGrad; a Secretaria Geral de Educação a Distância (SEaD) e a Secretaria Geral de Planejamento e Desenvolvimento Institucional (SPDI). A participação de outras instâncias na avaliação institucional conduziu a comunidade acadêmica a envolver-se e comprometer-se. A respeito da avaliação institucional participativa, Dias Sobrinho (2005) considera que esta é uma ação que ocorre em todos os setores da IES, é ampla e não se restringe aos resultados. Além disso, ela deve ser contínua no processo avaliativo, integrando a 
todos que compõem a comunidade acadêmica. Tal integração é construída no cotidiano, desde as ações administrativas e jurídicas até as pedagógicas, e tem na orientação da avaliação formativa a construção crítica do conhecimento que busca a qualidade. Isso não significa rejeitar a quantidade, mas fazer uso dos dados quantitativos, interpretá-los para atingir a qualidade educativa. Nesse processo, é preciso ter flexibilidade para a tomada de decisão coletiva e, assim, instituir a credibilidade entre os atores sociais para que possam comparar o que foi planejado com o que está sendo executado. Mesmo com algumas mazelas apresentadas nos processos de avaliação institucional, tais como a avaliação para entrega de relatório e para ranqueamento, é preciso avaliar e buscar o aprimoramento contínuo, pois se trata de investimento público e social.

Pode-se perceber que a CPA tanto atende a avaliação regulatória, por meio da obrigatoriedade de confeccionar os relatórios de autoavaliação institucional, como também atende a avaliação emancipatória, na medida em que abre brechas na regulação por meio da participação significativa da comunidade acadêmica e de instâncias institucionais no desenvolvimento da avaliação. Isso quer dizer que os resultados das avaliações interna e externa podem exercer o controle e impor a autoridade do Estado dentro das IES, pois elas têm que seguir as normas e as regras estabelecidas nas regulamentações federais e, com esse conhecimento, o Estado pode implementar políticas de regulação. Entretanto, Afonso (2009, p. 121) afirma que é possível estabelecer o "novo (des)equilíbrio" entre a regulação e a emancipação. Esse (des)equilíbrio é a avaliação emancipatória/formativa e ocorre com a participação da comunidade, que se torna ativa no processo de avaliação educacional, pois pode abrir brechas na avaliação regulatória e assegurar a passagem do estado de ignorância e passividade para o estado de autonomia, de emancipação e de solidariedade entre os atores sociais na avaliação educacional; logo, pode romper com atitudes deterministas.

O ponto de partida para abrir brechas na avaliação regulatória se dá por meio de atores que compõem a comunidade 
acadêmica. Eles podem ressignificar suas práticas por meio da participação, do envolvimento, da responsabilização e do comprometimento nos processos de avaliação institucional. Não significa participar para preencher um instrumento avaliativo, mas estabelecer a cultura de avaliação e de participação. Isso implica não aceitar de forma subserviente as normas/regulações impostas pelo Estado dentro da IES, mas conhecer e apreender as normas/regulações para construir práticas emancipatórias e formativas com base na avaliação.

A construção de práticas emancipatórias e formativas nos processos avaliativos conduz ao diálogo, à negociação e à tomada de decisão de acordo com a realidade institucional, pois os atores tornam-se conscientes de suas responsabilidades e compromissos. Com isso, a avaliação institucional se transforma em uma ferramenta valiosa para a gestão institucional.

\section{CONSIDERAÇÕES FINAIS}

Ao pensar se a autoavaliação desenvolvida pela CPA aproxima-se de uma perspectiva regulatória ou emancipatória, foi indispensável recorrer à trajetória histórica dos processos de avaliação institucional efetuados na universidade, o que foi o foco deste estudo. Um fato importante nesse contexto histórico é que já havia atores comprometidos, responsáveis e envolvidos com a melhoria institucional, pois eles já tinham a intenção de implantar um projeto de avaliação dos cursos de graduação, buscando o aperfeiçoamento do ensino. Até aquele momento, os cursos não possuíam o PPC, mas apenas a matriz curricular, a qual apresentava as disciplinas ofertadas. A adesão da IES ao Paiub possibilitou, de forma efetiva, a implantação do PPC, além de outras ações por meio do "Projeto de avaliação do ensino de graduação na UFSCar”.

Realizar processos de avaliação demanda tempo, além de gerar muito trabalho para os participantes. Nem toda a comunidade acadêmica percebe a importância da avaliação institucional para a tomada de decisão e para a gestão institucional, enfim, para a melhoria da IES. Contudo, a 
avaliação, ao longo dos anos, veio crescendo, mesmo que de maneira sutil. Cabe evidenciar que, dentro da instituição, há aqueles atores que fazem uso e querem a avaliação para a regulação, para a classificação e para o ranqueamento, como também há aqueles que fazem uso dos resultados na perspectiva emancipatória e formativa.

A trajetória de atuação da CPA mostrou haver oscilações na participação da avaliação institucional: em alguns momentos foi possível analisar o grande envolvimento da comunidade; contudo, houve outros em que a avaliação ficou a cargo da coordenação da comissão e de alguns atores que compõem a universidade. Como já mencionado, a consolidação da cultura de avaliação e de participação é conflituosa, não linear e heterogênea; há interesses diversos dentro do contexto requerendo da gestão da IES e da comunidade ações em prol da qualidade institucional.

Após seu primeiro ano, a CPA não apresentou maiores avanços nos processos de autoavaliação institucional. Dessa maneira, a comissão não se tornou, como já dito, suficientemente conhecida para ser então reconhecida pela comunidade acadêmica, ficando mais evidente em 2009, quando a universidade recebeu a visita da Comissão Externa do MEC, que constatou a fragilidade da comissão na condução e na sistematização dos processos de avaliação institucional.

Em decorrência dessa situação, uma nova equipe foi nomeada. Ao longo dos dois anos de mandato, essa nova CPA institucionalizada na universidade divulgou e informou as ações desenvolvidas para a comunidade acadêmica, buscando sensibilizá-la para a participação nos processos de autoavaliação institucional e demostrando a importância da avaliação na IES. Dessa maneira, a Comissão passou a ser conhecida e, assim, reconhecida por desencadear o processo de avaliação institucional nos moldes do Sinaes. No entanto, a comissão não conseguiu discutir com a comunidade os resultados da avaliação institucional pela falta de tempo hábil. Isso derivou do curto prazo imposto pelo Inep para o envio de relatório. Nota-se a ação de desarticulação do Estado em não consolidar os processos de autoavaliação, pois é imprescindível haver tempo para a avaliação, já que ela não se faz 
de um dia para o outro, mas é processual, gradativa, complexa e exige dos envolvidos a participação comprometida e responsável para entender como farão uso dos resultados na gestão institucional.

A CPA é um marco regulatório, o Estado regula e controla as IES por meio de normativas. No entanto, pode haver um novo (des)equilíbrio nesse processo de avaliação institucional nos moldes do Sinaes, que possibilita à CPA abrir brechas na avaliação regulatória para constituir a avaliação emancipatória. A partir da consolidação da cultura de avaliação e de participação da comunidade acadêmica, abrem-se brechas na avaliação regulatória para que os atores ressignifiquem a prática.

Diante dessas constatações, percebe-se que a autoavaliação institucional desenvolvida pela CPA em alguns momentos teve a predominância da avaliação regulatória, com o uso do resultado para regular e controlar o planejamento estratégico da IES, gerando o ciclo de responsabilização. Contudo, também houve momentos em que a avaliação emancipatória e formativa foram atuantes na condução dos processos avaliativos, nos quais foram notórios o envolvimento e a participação dos atores ressignificando suas práticas.

\section{REFERÊNCIAS}

AFONSO, Almerindo Janela. Reforma do Estado e políticas educacionais: entre a crise do Estado-nação e a emergência da regulação supranacional. Educação \& Sociedade, Campinas, v. 22, n. 75, p. 15-32, ago. 2001. Avaliação educacional: regulação e emancipação. 4. ed. São Paulo:

Cortez, 2009. 151 p.

BARREYRO, Gladys Beatriz; ROTHEN, José Carlos. “Sinaes” contraditórios: considerações sobre a elaboração e implantação do sistema nacional de avaliação da educação superior. Educação \& Sociedade, Campinas, v. 27, n. 96 - Especial, p. 955-977, out. 2006.

Para uma história da avaliação da educação superior brasileira: análise dos documentos do Paru, CNRES, Geres e Paiub. Avaliação: Revista da Avaliação da Educação Superior, Campinas, v. 13, n. 1, p. 131-152, mar. 2008. 
Avaliação da educação superior como política pública. In: ROTHEN, José Carlos; BARREYRO, Gladys Beatriz (Org.). Avaliação da educação: diferentes abordagens críticas. São Paulo: Xamã, 2011. p. 75-87.

BRASIL. Presidência da República. Casa Civil. Decreto n. 91.177, de 29 de março de 1985. Institui Comissão Nacional visando à reformulação da educação superior e dá outras providências. Brasília, DF, 1985. Disponível em: <http://www2.camara.leg.br/legin/fed/decret/1980-1987/decreto-9117729-marco-1985-441184-publicacaooriginal-1-pe.html>. Acesso em:

28 set. 2015.

. Lei n. 9.131, de 24 de novembro de 1995. Altera dispositivos da Lei n. 4.024, de 20 de dezembro de 1961, e dá outras providências. Brasília, DF, 1995. Disponível em: <www.planalto.gov.br/ccivil_03/leis/19131.htm>. Acesso em: 11 jul. 2014.

Decreto n. 2.026, de 10 de outubro de 1996. Estabelece procedimentos para o processo e avaliação dos cursos e instituições de ensino superior. Brasília, DF, 1996. Disponível em: <www.planalto.gov.br/ccivil_03/decreto/ Antigos/D2026.htm>. Acesso em: 11 jul. 2014.

. Medida Provisória n. 147, de 15 de dezembro de 2003. Institui o Sistema Nacional de Avaliação e Progresso do Ensino Superior e dispõe sobre a avaliação do ensino superior. Brasília, DF, 2003. Disponível em: <www.dji. com.br/medidas_provisorias/mp-000147-000-15-12-2003.htm>. Acesso em: 9 jul. 2014.

. Lei n. 10.861, de 14 de abril de 2004. Institui o Sistema Nacional de Avaliação da Educação Superior - Sinaes e dá outras providências. Brasília, DF 2004. Disponível em: <www.planalto.gov.br/ccivil_03/_ato2004-2006/2004/ lei/l10.861.htm>. Acesso em: 11 jul. 2014.

BRASIL. Ministério da Educação. Secretaria de Educação Superior. Portaria n. 130, de 14 de julho de 1993. Cria Comissão Nacional de Avaliação com o objetivo de estabelecer diretrizes e viabilizar a implementação do processo de avaliação institucional nas universidades brasileiras. In: Programa de Avaliação Institucional das Universidades Brasileiras. Brasília, DF: SESu, 1994. p. 33.

Lei n. 9.394, de 20 de dezembro de 1996. Estabelece as diretrizes e bases da educação nacional. Brasília, DF: MEC, 1996. Disponível em: <http:// portal.mec.gov.br/seed/arquivos/pdf/tvescola/leis/lein9394.pdf > . Acesso em: 10 jul. 2014.

Comissão Especial de Avaliação da Educação Superior (CEA). Bases para uma nova proposta de avaliação da educação superior. Brasília, DF: MEC/ INEP/ SESu, 2003. 127 p.

. Portaria n. 821, de 21 de agosto de 2009. Define procedimentos para avaliação de instituições de educação superior e cursos de graduação no âmbito do $1^{\circ}$ ciclo avaliativo do Sistema Nacional de Avaliação da Educação Superior e dá outras providências. Brasília, DF: MEC, 2009. Disponível em: <www.ufrgs.br/sai/regulacao/arquivos-regulacao/POR-2009-821-MEC_.pdf>. Acesso em: 9 jul. 2014. 
DIAS SOBRINHO, José. Campo e caminhos da avaliação: a avaliação da educação superior no Brasil. In: FREITAS, Luiz Carlos. Avaliação: construindo o campo e a crítica. Florianópolis: Insular, 2002. p. 13-62.

Avaliação institucional, instrumento da qualidade educativa: a experiência da Unicamp. In: DIAS SOBRINHO, José; BALZAN, Newton César (Org.). Avaliação institucional: teoria e experiências. 3. ed.

São Paulo: Cortez, 2005. p. 53-86.

LEITE, Denise. Caminho histórico da avaliação institucional no Brasil e em outros países. In: Avaliação e compromisso: construção e prática da avaliação institucional em uma universidade pública. Porto Alegre: Universidade, 2000. p. 28-74.

NEVO, David. School evaluation: internal or external? Studies in Educational Evaluation, Great-Britain, v. 27, p. 95-106, 2001.

RISTOFF, Dilvo Ilvo. Avaliação institucional: pensando princípios. In: DIAS SOBRINHO, José; BALZAN, Newton César (Org.). Avaliação institucional: teoria e experiências. 3. ed. São Paulo: Cortez, 2005. p. 37-52.

ROTHEN, José Carlos; DELANEZE, Taís; SANTOS, Joelma dos; SUDAN, Alessandra Maria; SOUZA, Maria Helena A. de Oliveira. Contribuições da atuação da Comissão Própria de Avaliação para a melhoria dos cursos de graduação da UFSCar no período 2004-2012. In: SEMINÁRIOS REGIONAIS SOBRE AUTOAVALIAÇÃO INSTITUCIONAL E COMISSÕES PRÓPRIAS DE AVALIAÇÃO (CPA) - 2013. Anais... São Paulo: PUC-São Paulo, 2013. p. 1-20.

SAUL, Ana Maria. Avaliação emancipatória: desafio à teoria e à prática de avaliação e reformulação de currículo. 2. ed. São Paulo: Cortez, 1991. 151 p.

SGUISSARDI. Valdemar. Universidade, fundação e autoritarismo: o caso da UFSCar. São Paulo: Estação Liberdade, 1993. 262 p.

UNIVERSIDADE FEDERAL DE SÃO CARLOS. Projeto de avaliação do ensino de graduação da UFSCar. São Carlos, SP: UFSCar, 1994. 40 p.

. Plano de Desenvolvimento Institucional. São Carlos, SP: UFSCar, 2005. 93 p. Perfil do profissional a ser formado na UFSCar. São Carlos, SP: UFSCar, 2008. $24 \mathrm{p}$.

Resolução ConsUni n. 652, de setembro de 2009. Dispõe sobre o regimento interno da Comissão Própria de Avaliação. São Carlos, SP: UFSCar, 2009. 4 p.

Portaria GR n. 397, de 19 de janeiro de 2010. Constitui a Comissão Própria de Avaliação da Universidade Federal de São Carlos. São Carlos, SP: UFSCar, 2010. 2 p.

Relatório de autoavaliação institucional da UFSCar 2011: Comissão Própria de Avaliação. São Carlos, SP: UFSCar, 2012. 286 p.

Relatório de autoavaliação institucional da UFSCar 2012: Sistema Nacional de Avaliação do Ensino Superior (Sinaes). São Carlos, SP: UFSCar, 2013. $263 \mathrm{p}$. 
WEBER, Silke. Avaliação e regulação da educação superior: conquistas e impasses. Educação \& Sociedade, Campinas, v. 31, n. 113, p. 1247-1269, out./dez. 2010.

JOELMA DOS SANTOS BERNARDES

Doutoranda no Programa de Pós-Graduação em Educação da UFSCar, São Carlos, São Paulo, Brasil

sjoelma82@yahoo.com.br

JOSÉ CARLOS ROTHEN

Professor da Universidade Federal de São Carlos (UFSCar), São Carlos, São Paulo, Brasil

josecarlos@rothen.pro.br 
